Conflict of Interest Statement: None of the authors has a financial relationship with a commercial entity that has an interest in the subject of this manuscript.

William N. Rom, M.D., M.P.H.

New York University School of Medicine

New York, New York

Kent E. Pinkerton, Ph.D.

Center for Health and the Environment

University of California, Davis

Davis, California

William J. Martin, M.D.

National Institute of Environmental Health Sciences

Research Triangle Park, North Carolina

Francesco Forastiere, M.D., Ph.D.

Rome E Health Authority

Rome, Italy

\section{References}

1. Hansen J, Sato M, Kharecha P, Russell G, Lea DW, Siddall M. Climate change and trace gases. Philos Transact A Math Phys Eng Sci 2007; 365:1925-1954.

2. IPCC fourth assessment report: climate change 2007 [Internet]. Geneva, Switzerland: Intergovernmental Panel on Climate Change [accessed 2007 Nov 20]. Available from: http://195.70.10.65/ipccreports/assessmentsreports.htm

3. Massachusetts v. Environmental Protection Agency. 549 U.S. _ (2007).

4. Epstein PR. Climate change and human health. N Engl J Med 2005;353: 1433-1436.

5. Haines A, Patz JA. Health effects of climate change. JAMA 2004;291: 99-103.

6. Basu R, Samet J. Relation between elevated ambient temperature and mortality: a review of the epidemiologic evidence. Epidemiol Rev 2002;24:190-202.

7. Ren C, Williams GM, Morawska L, Mengerson K, Tong S. Ozone modifies associations between temperature and cardiovascular mortality: analysis of the NMMAPS data. Occup Environ Med 2007:65:255-260.
8. Filleul L, Cassadou S, Medina S, Fabres P, Lefranc A, Eilstein D, Le Tertre A, Pascal L, Chardon B, Blanchard M, et al. The relation between temperature, ozone, and mortality in nine French cities during the heat wave of 2003. Environ Health Perspect 2006;114:1344-1347.

9. Stafoggia M, Forastiere F, Agostini D, Biggeri A, Bisanti L, Cadum E, Caranci N, de'Donato F, De Lisio S, De Maria M, et al. Vulnerability to heat-related mortality: a multicity population-based case-crossover analysis. Epidemiology 2006;17:315-323

10. Stafoggia M, Forastiere F, de'Donato F, Michelozzi P, Perucci CA, Agostini D, Caranci N, De Maria M, Miglio R, Rognoni M, et al. Factors affecting in-hospital heat-related mortality: a multicity casecrossover analysis. J Epidemiol Community Health 2007;62:209-215.

11. Yoganathan D, Rom WN. Medical aspects of global warming. Am J Ind Med 2001;40:199-210.

12. Mannino DM, Homa DM, Pertowski CA, Ashizawa A, Nixon LL, Johnson CA, Ball LB, Jack E, Kang DS. Surveillance for asthma: United States, 1960-1995. Morb Mortal Wkly Rep 1998;47:1-28.

13. Wayne P, Foster S, Connelly J, Bazzaz FA, Epstein PR. Production of allergenic pollen by ragweed (Ambrosia artemisiifolia L.) is increased in $\mathrm{CO}_{2}$ enriched atmospheres. Ann Allergy Asthma Immunol 2002;88: 279-282.

14. Liu S, Zhou Y, Wang X, Wang D, Lu J, Zheng J, Zhong N, Ran P. Biomass fuels are the probable risk factor for chronic obstructive pulmonary disease in rural South China. Thorax 2007;62:889-897.

15. Zhong N, Wang C, Yao W, Chen P, Kang J, Huang S, Chen B, Wang C, Ni D, Zhou Y, et al. Prevalence of chronic obstructive pulmonary disease in China: a large, population-based survey. Am J Respir Crit Care Med 2007;176:753-760.

16. Gold JA, Jagirdar J, Hay JG, Addrizzo-Harris D, Naidich DP, Rom WN. Hut lung: a domestically acquired particulate lung disease. Medicine 2000;79:310-317.

17. Haines A, Smith KR, Anderson D, Epstein PR, McMichael AJ, Roberts I, Wilkinson P, Woodcock J, Woods J. Policies for accelerating access to clean energy, improving health, advancing development, and mitigating climate change. Lancet 2007:370:1264-1281.

18. Chan M. Climate change and health: preparing for unprecedented challenges. The 2007 David E. Barnes global health lecture [Internet]. Bethesda, MD: World Health Organization; 2007 Dec 10 [accessed 2008 Mar 31]. Available from: http://www.who.int/dg/speeches/2007/ 20071211_maryland/en/index.html

\title{
Defining Transplantation and Listing Benefit in Patients with Chronic Obstructive Pulmonary Disease
}

Many chronic lung diseases demonstrate a progressive course with severe pulmonary dysfunction heralding high short-term mortality. Alternatively, patients with advanced chronic obstructive pulmonary disease (COPD) may suffer for years with significant symptoms, making it difficult to discriminate severely affected patients with COPD who have a high short-term risk of death from those with lower risk. Accordingly, it is challenging to appropriately time listing and performance of lung transplantation, which has its own risks, to significantly prolong life in these patients. In 2006, 31\% of lung transplants in the United States were for COPD, and 371 patients with COPD $(36 \%$ of those on a waitlist) were left waiting for a lung allograft $(1,2)$. The decision when to list and transplant patients with COPD affects organ utilization and therefore all lung transplant candidates.

Thabut and colleagues (3) provide important insights in this issue of the Journal (pp. 1156-1163). They develop models based on individual risk factors to predict median survival with and without transplant for patients with COPD. They then simulate these along with organ offer times to estimate survival gains or losses from time of listing. Although some have suggested that risk with transplantation always exceeds risk without transplantation for COPD $(4,5)$, Thabut and colleagues argue that listing for lung transplantation prolongs life for approximately $50 \%$ of patients under a waiting time-based allocation system.

Proper interpretation of Thabut and colleagues' results requires careful consideration of their definition of benefit. These investigators address a two-part question: If waitlisted under the former waiting time-based allocation system in the United States, would a patient with COPD (1) live until offered a lung allograft and (2) upon transplantation, have a longer, shorter, or similar survival than if never waitlisted? If a patient dies during the simulated wait time, then listing was futile. If a patient survives long enough to be transplanted in the simulation, overall survival may be better, worse, or no different than the natural history of that individual's disease.

Patient 2 in Figure E4 of the online supplement conceptualizes this idea. This patient has an estimated 2-year waitlist survival time but a 3-year waiting time. Their algorithm therefore assigns a benefit of zero, because Patient 2 did not survive long enough to be impacted positively or negatively by transplant. If, 
however, this same patient had been transplanted a few days after listing, he would have lived 1 year post-transplant, but lost a year of life overall. Therefore, Thabut and colleagues' ascribed "transplant benefit" may more accurately be described as "listing benefit," because some simulated patients don't survive to see a transplant benefit (or risk).

Although calculated using many common variables, Thabut and coworkers' estimated listing benefit should not be confused with transplant benefit, as defined in the Lung Allocation Score (LAS) (6), which is used to prioritize patients for lung transplantation in the United States. First, as opposed to median survival gains due to listing, the LAS estimates patient-days gained or lost over the year after a lung transplant. In contrast to Thabut and colleagues' simulations, the LAS does not consider wait times, the probability of surviving until an offer, or outcomes after 1 year, but it does estimate transplant benefit for all listed patients. LAS benefit projections recorded for patients with emphysema/COPD transplanted from May 2005 to June 2007 had $12.7 \%$ of transplanted patients with positive 1-year transplant benefit and, using a longer projection, $22.0 \%$ with positive 3-year benefit (7).

Another difference between Thabut and colleagues' listing benefit and LAS transplant benefit centers on those simulated patients who live long enough to get transplanted in the model. Because better waitlist survival is likely correlated with both living until being offered an allograft and post-transplant outcomes, Thabut and coworkers' simulation results may be weighted toward healthier patients. As fewer patients with poor waitlist survival get the opportunity for transplant in the simulation, the listing benefit calculations may be less applicable to patients ordered by LAS. Sicker patients actually get a better chance at allocation under the LAS system, potentially resulting in worse post-transplant outcomes, although this is yet to be determined.

Some take a broader view of benefit than is reflected in the relatively simplistic estimates of both Thabut and colleagues and the LAS. Although prolonging survival is an important goal, impact on quality of life is another crucial consideration. Many patients would gladly trade years of life burdened with severe COPD for the same or smaller number of years of an active post-transplant lifestyle. Although controversial, our fiduciary responsibility to patients may warrant listing and transplanting such individuals despite a lack of survival benefit.

Thabut and coworkers observed that double-lung transplantation had a lower estimated risk than single-lung transplantation. The inclusion of procedure type in modeling post-transplant outcomes poses some difficulty. Often, a patient with COPD may be eligible for either a single- or double-lung transplant and accept whichever is offered first. At listing, it may be unclear which procedure the patient will eventually receive, making it impossible to divine what the listing benefit will actually be. Of course, whether procedure choice itself confers a survival benefit is controversial and will unlikely be answered in an entirely unbiased fashion by nonrandomized studies.

Thabut and colleagues aim to help a clinician decide if a patient with COPD should be listed for transplant, based on the historical wait times and experience in the United Network for Organ Sharing. As advised by the authors, this model should not be used clinically until externally validated. The dramatic alteration in wait times and organ allocation from the LAS score might affect the accuracy of this system based on the older system and purely on time waiting. In addition, patients with COPD who did not necessarily need immediate transplantation were often waitlisted to accrue time under the old system. This means that patients whom we might consider to waitlist for transplant in 2008 may be an entirely different subset (or at a different point in their disease course) from those used to derive both Thabut and colleagues' models and the LAS. Therefore, we await further studies in the United States and around the world to help decide when "to transplant or not to transplant" patients with COPD.

Conflict of Interest Statement: Neither author has a financial relationship with a commercial entity that has an interest in the subject of this manuscript.

\author{
Susan Murray, Sc.D. \\ University of Michigan School of Public Health \\ and \\ Scientific Registry of Transplant Recipients \\ Ann Arbor, Michigan \\ Steven Kawut, M.D., M.S. \\ College of Physicians and Surgeons \\ and \\ Joseph L. Mailman School of Public Health \\ Columbia University \\ New York, New York
}

\section{References}

1. Mulligan MS, Shearon TH, Weill D, Pagani FD, Moore J, Murray S. Heart and lung transplantation in the United States, 1997-2006. Am J Transplant 2008;8:977-987.

2. Annual report of the U.S. Organ Procurement and Transplantation Network and the Scientific Registry of Transplant Recipients: transplant data 1997-2006. Rockville, MD: Health Resources and Services Administration, Healthcare Systems Bureau, Division of Transplantation; 2007.

3. Thabut G, Ravaud P, Christie JD, Castier Y, Fournier M, Mal H, Lesèche G, Porcher R. Determinants of the survival benefit of lung transplantation in patients with chronic obstructive pulmonary disease. Am J Respir Crit Care Med 2008;177:1156-1163.

4. Hosenpud JD, Bennett LE, Keck BM, Edwards EB, Novick RJ. Effect of diagnosis on survival benefit of lung transplantation for end-stage lung disease. Lancet 1998;351:24-27.

5. Stavem K, Bjortuft O, Borgan O, Geiran O, Boe J. Lung transplantation in patients with chronic obstructive pulmonary disease in a national cohort is without obvious survival benefit. $J$ Heart Lung Transplant 2006;25:75-84.

6. Egan TM, Murray S, Bustami RT, Shearon TH, McCullough KP, Edwards LB, Coke MA, Garrity ER, Sweet SC, Heiney DA, et al. Development of the new lung allocation system in the United States. Am J Transplant 2006;6:1212-1227.

7. U.S. Organ Procurement and Transplantation Network; United Network for Organ Sharing. OPTN/UNOS data. Paper presented at: OPTN/UNOS Thoracic Organ Transplantation Committee Meeting; October 2, 2007; Chicago, IL.

DOI: $10.1164 / \mathrm{rccm} .200802-275 E D$

\section{Predicting Tuberculosis Does the IGRA Tell the Tale?}

The tuberculin skin test (TST) has been used to diagnose infection with Mycobacterium tuberculosis for close to 100 years.
This longevity reflects the TST's low cost and ease of administration, as well as the numerous longitudinal studies correlating 